\title{
REBELIÓN Y SHARÍA EN EL SAHEL: UNA APROXIMACIÓN AL ESTALLIDO DE LA REBELIÓN TUAREG Y LA OCUPACIÓN DEL NORTE DE MALI POR GRUPOS YIHADISTAS E ISLAMISTAS ARMADOS
}

\author{
David Nievas ${ }^{1}$
}

Universidad Autónoma de Madrid (UAM)

\begin{abstract}
Resumen:
Mali ha sufrido en 2012 y 2013 uno de los periodos de crisis más graves que se recuerdan en su historia contemporánea. Este trabajo pretende aportar elementos para comprender los principales actores que han protagonizado el levantamiento tuareg en el norte de Mali y la posterior ocupación por parte de grupos yihadistas e islamistas durante cerca de 10 meses.
\end{abstract}

Palabras clave: Mali, rebelión tuareg, yihadismo, islamismo, Ansar Din, AQMI, MUYAO.

Title in English: "Rebellion and Sharia in the Sahel: an Analysis of the Tuareg Rebellion and the Occupation of Northern Mali by Armed Jihadist and Islamist Groups”.

\section{Abstract:}

In 2012 and 2013 Mali suffered one of the worst periods of crisis in its recent history. This article provides insights into the key players who have shaped the Tuareg rebellion in northern Mali and the subsequent tenmonth occupation by jihadist and Islamist groups.

Keywords: Mali, Tuareg Rebellion, Jihadism, Islamism, Ansar Din, AQIM, MUJWA.

Copyright $@$ C UNISCI, 2014.

Las opiniones expresadas en estos artículos son propias de sus autores, y no reflejan necesariamente la opinión de UNISCI. The views expressed in these articles are those of the authors, and do not necessarily reflect the views of UNISCI.

\footnotetext{
${ }^{1}$ David Nievas Bullejos realiza un doctorado en Estudios Árabes e Islámicos en la Universidad Autónoma de Madrid y es becario FPU-MEC.

E-mail: david.nievas@uam.es.

http://dx.doi.org/10.5209/rev_UNIS.2013.n34.4483]
} 


\section{Introducción}

Mali ha vivido en 2012 uno de los periodos de crisis más graves que se recuerdan en su historia contemporánea. El país ha sufrido una doble crisis, una en la mitad norte que acabó con la presencia del Estado y una crisis institucional en el sur y la capital, Bamako, provocada por el golpe de Estado del 22 de marzo 2012. Nos centraremos en la crisis del norte aunque también citaremos la crisis en el sur ya que creemos que están asociadas. El norte ha vivido una ocupación por parte de grupos armados islamistas durante cerca de 10 meses, desde abril 2012 hasta enero 2013. Para tratar de comprender lo acontecido creemos que hay una necesidad de ir más allá del enfoque securitario e integrar en el análisis otras perspectivas. El objetivo es un conocimiento con matices de los principales actores implicados y los contextos en los que han ejercido su dominio. Todo empezó el 17 de enero de 2012 con el estallido de la rebelión tuareg a cargo del Movimiento de Liberación Nacional del Azawad (MNLA). Esta derivó en una insurrección tuareg e islamista con el grupo Ansar Din a la que se añadieron los grupos autoproclamados yihadistas de Al Qaeda en el Magreb Islámico (AQMI) y el Movimiento por la Unicidad y la Yihad en África Occidental (MUYAO) los cuales finalmente tomaron el control de la mayoría del territorio. Creemos que lo sucedido en el norte de Mali es una crisis donde confluyen varios factores y donde existen unos matices que es conveniente tomar en cuenta a la hora de abordar el conflicto.

No podemos olvidar que estos acontecimientos ocurren en el desierto del Sáhara, un inhóspito y vasto espacio de miles de kilómetros y muy poco habitado que posee su propia naturaleza y códigos. Como apuntó en 2007 Baz Lecocq, uno de los grandes conocedores de la región, los acontecimientos en el Sáhara vienen determinados por la naturaleza del desierto. La falta de medios de comunicación hacen que la rumorología sea la principal fuente de información y ésta pocas veces escapa a la manipulación debido a los antagonismos existentes entre las etnias, clanes y pueblos, por lo que es difícil interpretar sin un conocimiento del contexto $^{2}$. Por tanto, este trabajo es un intento de aproximación a los factores que provocaron esta crisis y que hicieron posible la ocupación del norte de Mali durante 10 meses. Para analizar la situación creemos que es necesario tener en cuenta varios aspectos que intentaremos desgranar en este artículo. Pretendemos huir de la simplificación de que lo que ha sucedido es un problema de terrorismo internacional. Si bien, somos conscientes de las limitaciones de nuestro trabajo debido al difícil acceso a la información y lo cambiante de la situación en el norte de Mali.

\section{Un convulso norte de Mali}

\subsection{Una antigua reivindicación tuareg}

Para una comprensión de lo acontecido en el norte de Mali desde que estalló la rebelión tuareg en enero de 2012 hasta la intervención militar francesa de inicios de 2013 es necesario echar la vista atrás para obtener una perspectiva histórica. La lucha del movimiento tuareg por la autodeterminación en la zona del Sahel en general, y en Mali en particular, tiene más de cincuenta años. Mali accedió a la independencia de Francia el 22 de septiembre de 1960.

\footnotetext{
${ }^{2}$ Lecocq, Baz y Shrijver, Paul: "The War on Terror in a Haze of Dust: Potholes and Pitfalls on the Saharan Front", Journal of Contemporary African Studies, vol. 25, $\mathrm{n}^{\circ} 1$ (2007), p. 143, en http://www.foreignpolicy.com/files/fp_uploaded_documents/120608_War\%20on\%20Terror\%20JCAS\%20offpri nt\%20(2).pdf.
} 
Apenas dos años después, una parte de la comunidad tuareg se sublevó contra las autoridades poscoloniales de Bamako en la primera rebelión en el norte del país. Desde entonces el levantamiento armado tuareg ha sido una constante en la historia maliense. Hay unas motivaciones que han empujado a esta comunidad nómada a levantarse en armas a lo largo de la historia contra las autoridades centrales de Bamako en forma de diferentes rebeliones armadas.

La última rebelión, iniciada a principios de 2012, es la cuarta en la historia de las sublevaciones tuaregs en Mali y ha sido protagonizada por el Movimiento de Liberación Nacional del Azawad (MNLA en adelante) dando como resultado una grave crisis en la mitad norte sin precedentes en su historia. El MNLA nació en 2011 tras la unión de varios grupos tuaregs tradicionales que apostaron por un antiguo propósito, la independencia del Azawad. El llamado Azawad es una amplia extensión geográfica, equivalente a la dimensión de una España y media, que en la tradición tuareg comprende las actuales regiones administrativas de Kidal, Tombuctú y Gao situadas en el norte de Mali. Tras el recorte colonial de África y el acceso a las independencias, las amplias zonas de pastoreo de los comunidades nómadas tuareg quedaron bajo jurisdicción de Estados independientes como Mali, Argelia, Níger o Libia que levantaron fronteras en el extenso área del espacio Sáhara-Sahel. El territorio del Azawad y sus diversas poblaciones quedaron enmarcadas en el actual Estado de Mali. Actualmente, las tres regiones malienses de lo que los tuaregs denominan el Azawad ocupan ligeramente más de dos terceras partes de la República. A pesar de su amplitud, esta zona apenas está poblada con cerca de un millón y medio de personas, equivalente a un $10 \%$ de la población total de Mali que se concentra especialmente en las grandes ciudades.

El nacionalismo tuareg, enraizado en los efectos de la colonización europea de África, ha sido moldeado por décadas de marginalización y opresión. En los nuevos Estados independientes del África Occidental la comunidad tuareg era una minoría aislada de los centros de poder, no solo geográficamente sino también culturalmente. Cuando las autoridades francesas coloniales se retiraron de Mali, dejaron el poder en manos de los movimientos políticos dominados por las etnias negroides, mayoritarias en el sur. La comunidad tuareg ya había manifestado su intención de que se le concediese un territorio propio en el Sáhara que estuviese separado de la mayoría negroide del sur, pero las autoridades francesas lo rechazaron ${ }^{3}$. En consecuencia, al llegar la independencia el descontento tuareg fue mayúsculo. Pronto, comprobaron los pocos lazos que les unían con el nuevo Estado maliense en construcción. En este contexto, estalló la primera rebelión tuareg que Modibo Keita (1960-1968), primer presidente y padre de la independencia de Mali, sofocó duramente. En lo sucesivo, grandes zonas norteñas habitadas por poblaciones nómadas tuaregs se convirtieron en distritos militares y fueron ignoradas en las inversiones económicas durante décadas. Las sublevaciones y protestas tuaregs se abordaron desde entonces por Bamako como un problema a solucionar militarmente. Asimismo, la zona del norte, alejada del centro neurálgico que se estaba construyendo en la capital maliense, se convirtió en el lugar de abandono y exilio de los presos políticos, en especial bajo el régimen militar de Moussa Traoré (1969-1990).

El infradesarrollado norte del país era muy vulnerable a las sequías que se produjeron periódicamente en la zona, en especial en los años setenta y ochenta (1972-73, 1984-85). Las consecuencias de estas sequías fueron mortales para las comunidades de pastoreo del norte de

\footnotetext{
${ }^{3}$ Ould Cheikh, Mohamed Mahmud: "Lettre ouverte adressée au géneral de Gaulle, signée par 300 chefs locaux (30 mai 1958)", Questions internationales, Le Sahel en crises, no 58 (noviembre-diciembre 2012), p. 122.

${ }^{4}$ De Benoist, Joseph Roger (1998): Le Mali, Paris, Harmattan, p. 124
} 
Mali y la economía rural en general. Como resultado una segunda rebelión estalló en 1985 y los jóvenes tuaregs comenzaron a emigrar a los países de la región ricos en petróleo, en especial Argelia y Libia. La Libia de Muammar Gadafi acogió a muchos de ellos y se integraron en las llamadas "legiones islámicas" del ejército libio. Cientos de tuaregs fueron enviados a combatir en los años 80 a Líbano y en la guerra fronteriza de Libia contra Chad. A cambio, la comunidad tuareg obtuvo cierto apoyo del líder libio en sus reivindicaciones ${ }^{5}$.

La larga lucha por la autodeterminación no es una ideología que hace unanimidad entre los tuaregs y ni mucho menos entre la población del norte de Mali. La comunidad tuareg tiene una compleja forma de organización que descansa sobre estructuras tribales y una jerarquía muy marcada. Esta fragmentación hace que las múltiples rivalidades entre facciones alimenten constantes disputas intestinas dentro de la comunidad ${ }^{6}$. Incluso, muchos tuaregs consideran como legítimos los Estados donde residen desde hace décadas y están integrados en ellos. Además, la región del Sahel Occidental y concretamente el norte de Mali ha sido tradicionalmente una zona de intercambio cultural entre el norte de África, el espacio SáharaSahel y el África al sur del Sáhara. En este amplio espacio grandes poblaciones de diversos orígenes étnicos y culturales han convivido durante siglos. Se cree que la comunidad tuareg no representa más del $30 \%$ de la totalidad de la población del norte de Mali. El resto la componen diversas etnias como los fulani, los árabes (mayoritariamente en Tombuctú), los kounta, los peuls sedentarios y los agricultores y artesanos songhai (especialmente mayoritarios en la región de Gao). El porcentaje que tienen cada una de las etnias y su distribución es difícil de conocer, sin embargo ha existido una tradicional simplificación local de la distinción racial entre el "blanco" referido a los tuaregs y los árabes, y "el negro africano" referido a los songhais y otras etnias negroides ${ }^{7}$. La pertenencia étnica ha sido de relevancia por la función tradicional de solidaridad y de protección, además de las relaciones políticas de alianzas que se han dado entre los grupos en especial en los años noventa cuando emergió un nacionalismo songhai para contrarrestar el nacionalismo tuareg. Con el paso de los años, las violencias asociadas a las rebeliones y una retirada del Estado maliense en el norte en los últimos dio como consecuencia un incremento de las tensiones entre la diversidad de grupos étnicos que fue importante en la actual crisis que tratamos ${ }^{8}$. El gobierno del presidente maliense Amadú Tumani Turé (2002-2012) se retiró progresivamente del norte de Mali pero fomentó la creación de milicias basadas en el origen étnico para intentar controlar la región ante los rebeldes tuaregs ${ }^{9}$.

En el inicio de los años noventa los profundos cambios en dirección a la democracia que experimentó Mali beneficiaron a las reivindicaciones tuaregs. En el verano de 1990,

\footnotetext{
5 Para más información sobre la "contradictoria e irónica" relación de Gadafi con los tuaregs, véase, Dörrie, Peter: "The origins and consequences of tuareg nationalism", World Politics Review, 9 de mayo 2012, en http://www.worldpoliticsreview.com/articles/11922/the-origins-and-consequences-of-tuareg-nationalism.

${ }^{6}$ Algunos analistas observan que la crisis del norte de Mali que abordamos en este trabajo es debida en primer lugar a una rivalidad entre elites tuareg y otras comunidades del norte. Lacher, Wolfram y Tull, Dennis M.: "Mali: Beyond counterterrorism", SWP Comments, German Institute for International and Security Affairs, $\mathrm{n}^{\circ} 7$ (febrero 2013), p.2, en http://www.swp-berlin.org/fileadmin/contents/products/comments/2013C07_lac tll.pdf. ${ }^{7}$ Lecocq, Baz; Mann, Gregory; Whitehouse, Bruce; Badi, Dida; Pelckmans, Lotte; Belalimat, Nadia; Hall, Bruce S. y Lacher, Wolfram: "One hippopotamus and eight blind analysts: A multivocal analysis of the 2012 political crisis in the divided republic of Mali. extended editors cut", Review of African Political Economy, $\mathrm{n}^{\circ} 137$ (2013), p. 2, en http://media.leidenuniv.nl/legacy/lecocq-mann-et-al---one-hippo-8-blind-analysts-editors-cut.pdf. ${ }^{8}$ Ibid.

${ }^{9}$ Por ejemplo, apoyó la creación de milicias árabes a cargo de Ould Meydou, árabe del valle de Tlemsi, en la región de Gao, y milicias tuaregs a cargo de Ag Gamou, tuareg Imghad, comunidad vasalla del clan tuareg de los Ifoghas; International Crisis Group: "Mali: eviter l'escalade”, Rapport Afrique, no 189 (18 julio 2012), p.4, en http://www.crisisgroup.org/ /media/Files/africa/west-africa/mali/189-mali-eviter-l-escalade.
} 
coincidiendo con el desmoronamiento del deslegitimado y en bancarrota régimen militar del general Moussa Traoré, el movimiento tuareg inició una nueva rebelión que provocó una violencia generalizada. Las represalias militares de Bamako en el norte fueron importantes y provocaron el éxodo masivo de civiles que han marcado la memoria viva de las poblaciones del norte. El 6 de enero de 1991 se llegó a un acuerdo de paz con la mediación de Argelia en la localidad de Tamanrasset que previó la descentralización y la reintegración de los tuareg en las fuerzas armadas. El régimen militar de Moussa Traoré cayó finalmente el 26 de marzo 1991 tras el alzamiento popular prodemocrático y un golpe de Estado militar ${ }^{10}$. En medio de estos momentos de cambio, se satisficieron algunas reivindicaciones tuaregs. Se concedió cierta autonomía territorial y líderes y miembros del movimiento se insertaron en el ejército y en la administración maliense. Tras la firma del Pacto Nacional en 1992 entre el gobierno y los principales grupos rebeldes, se destinaron grandes sumas de dinero al desarrollo del norte en vistas a la aplicación de un estatuto particular y la descentralización prevista en la nueva y democrática Constitución de 1992. Sin embargo, las principales clausulas del Pacto Nacional nunca han visto la luz ${ }^{11}$.

Años más tarde, en 2005, el nuevo inquilino del palacio de Koulouba, el antiguo héroe del alzamiento popular de los noventa, Amadou Toumani Touré (conocido como ATT), creó la Agencia Maliense para el Desarrollo en el Norte de Mali, un organismo para trabajar en la inversión y desarrollo en las regiones del norte pero la rebelión se reactivó en mayo de 2006. Las reivindicaciones seguían siendo en general similares que en las pasadas rebeliones y que se habían exigido a las autoridades centrales en 1992, a saber, una reforma económica y política y más posibilidades de mejora de los tuaregs que habían integrado el ejército maliense ${ }^{12}$. Del mismo modo que en los anteriores levantamientos, el fin de la rebelión siguió el mismo patrón y Argelia y Libia hicieron de mediadores entre los rebeldes tuaregs y el gobierno de Mali y de Níger, donde también había estallado el levantamiento. Ambos gobiernos hicieron algunas concesiones ${ }^{13}$. En los sucesivos años y hasta poco antes del estallido de la cuarta insurrección en 2012, la situación en el norte de Mali vino marcada por una paz frágil amenazada por el grupo del líder tuareg Ibrahim Ag Bahanga ${ }^{14}$. Este tuareg mantuvo viva la llama de la rebelión atacando y secuestrando soldados del ejército maliense ${ }^{15}$.

\footnotetext{
${ }^{10}$ El golpe de Estado fue protagonizado por un joven militar y futuro presidente, Amadou Toumani Touré (ATT), que más tarde se retiró del primer plano político para dejar al estamento civil gestionar la transición a través de Comité para la transición. Se votó una constitución democrática que el 98,35\% de los votantes aprobó el 12 de enero de 1992. De Benoist, op. cit., p.225. Desde entonces, y hasta el golpe de Estado del 22 de marzo de 2012, los cambios en la presidencia del gobierno se han realizado en las urnas.

11 "Pacte National Conclu Entre Le Gouvernement De La République Du Mali Et Les Mouvements Et Fronts Unifiés De l'Azawad Consacrant Le Statut Particulier Du Nord Du Mali", en

http://news.abamako.com/documents/docs/Pacte_National_annexes.pdf.

${ }^{12}$ Lecocq et al., op. cit., p. 155.

${ }^{13}$ Como la desmilitarización del norte a favor de unidades militares de antiguos rebeldes. Los acuerdos fueron mejor respetados en el vecino Níger lo cual contribuyó a que la rebelión tuareg de 2012 no tuviera eco en su territorio. Níger ha integrado a notables tuaregs y a antiguos dirigentes rebeldes en los órganos de decisión nacional y local. El antiguo líder tuareg Rhissa Ag Boula es consejero del presidente Mahamadou Issoufou desde 2011 y el primer ministro, Brigi Rafini, es un notable tuareg. Asimismo el país ha avanzado hacía una mayor descentralización regional, reclamada por los antiguos movimientos rebeldes. Dörrie, op. cit; Deycard, Fréderic (2013): Les Touaregs du Niger et la crise du Sahel, Sahel - Éclairer le passé pour mieux dessiner l'avenir, GRIP, pp. 19-40.

${ }^{14}$ En 2007 los acuerdos fueron rechazados por una parte de los tuareg, como la Alianza Tuareg Níger-Mali (ATNM) y los ataques continuaron liderados por el líder tuareg Ibrahim Ag Bahanga.

${ }^{15}$ Para algunos observadores la rebelión protagonizada por Ag Bahanga tenía su causa en las tensiones internas dentro de la sociedad tuareg, que tuvo lugar esencialmente entre las tropas de Bahanga, provenientes de Kidal y las tropas tuareg integradas en las filas del ejército maliense o apoyadas por Bamako, muchas de las cuales eran Imghad o tribus consideradas no nobles, al contrario que los Ifoghas o los árabes berabiches; International Crisis Group, op. cit., p.3.
} 
Asimismo, el intercambio de acusaciones y recriminaciones por el incumplimiento de los Acuerdos de Argel de 2006 era constante. En febrero 2011, el presidente ATT anunció la promesa de poner en marcha un nuevo programa para el desarrollo del norte y la búsqueda de la paz y la seguridad con el fin de aliviar el descontento tuareg. Seis meses después se puso en marcha el Programa por la Seguridad, la Paz y el Desarrollo del Norte (PSPDN) con un presupuesto de 32 mil millones de francos CFA (65 millones de dólares) ${ }^{16}$.

Sin embargo, el incumplimiento de las promesas y las viejas heridas de los años noventa empujaron a una parte frustrada de la comunidad tuareg a organizar una nueva rebelión en 2012. Algunos factores ayudaron a tomar este camino. La caída del coronel Gaddafi en Libia, el regreso de los combatientes tuaregs y la diseminación de sus arsenales militares en el Sahel insufló energía a los grupos tuaregs interesados en la independencia. Pero lo que tornaría diferente el resultado de la cuarta rebelión fue la aparición de otros actores armados. Los grupos islamistas y yihadistas, establecidos desde hace tiempo en una especie de santuario en el norte de Mali, entraron en acción con el estallido de la nueva insurrección.

\subsection{2: una rebelión tuareg diferente}

Cientos de combatientes tuaregs regresaron de Libia fuertemente armados después de la caída del líder libio y se integraron en Mali según sus líneas clánicas. Algunos retornaron al ejército maliense. Otros se sumaron a veteranos combatientes que esperaban en Mali y a un serie de jóvenes tuareg para fundar el MLNA ${ }^{17}$. En cualquier caso, la influencia de la crisis de Libia, que dejó a muchos milicianos desempleados y la apertura de los arsenales militares libios, no debe de ser entendida como la única explicación de la crisis. La militarización de las milicias fue rápida y clave en el resurgimiento de la nueva rebelión, pero ésta no se entendería sin la historia de las insurrecciones anteriores ${ }^{18}$. Posiblemente cualquier otro desarrollo de los acontecimientos en Libia hubiese llevado a un estallido de la rebelión separatista en Mali tarde o temprano.

No podemos olvidar los factores en los que coinciden en mencionar algunos autores. Es necesario tomar en cuenta la rivalidad interna entre las facciones tuaregs como una de las principales causas de la insurrección armada, junto con la corrupción de las estructuras centrales y el impacto desestabilizador del narcotráfico en el cual el gobierno de Bamako se había apoyado durante los últimos años para controlar el norte ${ }^{19}$. Pero las viejas heridas y una larga lista de promesas incumplidas por el gobierno de Bamako hicieron sentir una frustración en los combatientes veteranos tuaregs que se sumó a la nueva energía de los jóvenes en la diáspora, y en consecuencia, les hizo confluir para tomar el camino de la lucha por la

\footnotetext{
${ }^{16}$ El programa ponía el acento en proyectos ligados a la seguridad, las mujeres y a los jóvenes. Era encabezado por un tuareg de origen de Kidal, Mohamed Ag Erlaf y recibía subvenciones de los principales fondos mundiales de desarrollo, como el PNUD o el Banco Mundial y la UE. Gran parte de la comunidad tuareg no creyó en la promesa y vio el programa como una forma de incrementar la presencia militar del gobierno de Bamako en el norte del país; Ibid., p. 7.

${ }^{17}$ Es de destacar que una vez más no todos los tuareg apoyaron el proyecto secesionista, y algunos líderes incluso ponen sus fuerzas militares al servicio de Mali, como el líder militar Ag Gamou.

${ }^{18}$ Máxime cuando los arsenales pertenecientes a los grupos armados encontrados por las fuerzas de intervención armadas francesas y chadianas en el norte son en su mayoría armas del ejército maliense que abandonó o que vendió a estos grupos; Conflict Armament Research y Small Arms Survey: "Rebel forces in northern mali. documented weapons, ammunition and related materiel", (2013), en http://www.smallarmssurvey.org/fileadmin/docs/E-Co-Publications/SAS-SANA-Conflict-Armament-ResearchRebel-Forces-in-Northern-Mali.pdf.

${ }^{19}$ El gobierno de Bamako se apoyó en facciones tuaregs vasallas de los clanes aristócratas así como en tribus árabes de Tombuctú y Gao, lo que permitió a éstos una libertad de actuación para participar del tráfico de estupefacientes que cruza el Sahel hacia Europa. Lacher y Tull, op. cit., p 2.
} 
independencia. Las facciones tuareg se reunieron en la localidad de Zakak, en el norte de Mali, en octubre de 2011 para dar inicio a las discusiones sobre la idoneidad de lanzar una nueva rebelión, la organización y el liderazgo de la misma ${ }^{20}$. Hay que señalar que el belicoso líder rebelde, Ag Bahanga, murió en un accidente de coche en el desierto maliense pero este contratiempo no interrumpió la fuerte movilización del movimiento. En la reunión se decidió nombrar a un retornado de Libia, Bilal Ag Sharif, como presidente del movimiento y a Mohamed Ag Najim como jefe militar, y se consensuó que el principal objetivo del recién creado MNLA era acabar con la "ocupación ilegal del gobierno de Bamako del Azawad" y la independencia del Azawad ${ }^{21}$.

En enero de 2012, la ofensiva armada del MNLA comenzó en el norte de Mali. El inicio de la nueva rebelión no fue ninguna sorpresa para el gobierno central del presidente ATT que, al tanto de las discusiones en el seno del movimiento tuareg, había intentado evitar el estallido de las hostilidades. Después de culpar al gobierno de Bamako de provocar militarmente al movimiento y de no cumplir sus promesas en el norte, el MNLA emprendió definitivamente el ataque a las guarniciones del ejército en Ménaka, en la región de Gao. Rápidamente, los ataques se extendieron a otras zonas de las regiones del extremo norte de Mali, como Aguelhoc en la región de Kidal ${ }^{22}$. El 17 de febrero, un mes después del inicio de la ofensiva, se comprobó que la insurrección no era como las anteriores. La intensidad de los combates era mayor que en otras ocasiones y se sospechaba de que otros grupos armados, presentes en la zona pero que hasta el momento no se habían enfrentado en campo abierto al ejército maliense, se habían sumado a la ofensiva tuareg ${ }^{23}$. El 11 de marzo 2012 el rápido avance rebelde obligó al ejército a retirarse a Tessalit, pequeña localidad en la provincia de Kidal, donde mantenía un estratégico bastión. El MNLA reclamó victoria mientras que el fragmentado y pobremente armado ejército de Mali anunciaba una "retirada estratégica"24.

\footnotetext{
${ }^{20}$ Para más información sobre la reunión de Zakak, véase, International Crisis Group, op. cit., p 11.

${ }^{21}$ Hasta la fecha, la división en el movimiento tuareg había sido la tónica, pero en esta rebelión se hizo énfasis en la unidad. Para más información sobre la división de los grupos armados tuaregs desde los años noventa, véase, Morgan, Andy: "The causes of the uprising in northern Mali", Think Africa Press, 6 de febrero 2012, en http://thinkafricapress.com/mali/causes-uprising-northern-mali-tuareg

${ }^{22}$ Las primeras consecuencias de la reanudación de la rebelión y la fuerte capacidad de ataque del MNLA fueron nefastas políticamente para la administración de ATT. A primeros de febrero tuvieron lugar manifestaciones en la ciudad de Kati, a las afueras de Bamako, donde se encuentra una de las principales guarniciones militares. Como un aviso de lo que pasaría meses más tarde con el golpe de Estado militar, las mujeres de los soldados destinados en el norte denunciaron las pésimas condiciones de equipamiento y armamento que poseían sus maridos e hijos para combatir.

${ }^{23}$ Se difundieron rumores de la participación de grupos como Al Qaeda en el Magreb Islámico, en especial por el gobierno de Bamako. La información que llegaba desde el desierto maliense era escasa y se confundía con la intención del gobierno de ATT de desprestigiar al movimiento tuareg.

${ }^{24}$ En esta fase de la insurrección tuvo lugar el sangriento episodio de Aguelhoc. En esta localidad cercana a la ciudad de Kidal se tiene constancia de que, después de su conquista por fuerzas rebeldes tuaregs, cerca de un centenar de soldados malienses fueron tomados prisioneros para más tarde ser ejecutados a sangre fría. Videos e imágenes de los cadáveres tomadas con teléfonos móviles circularon en todo el país, en especial en Bamako, levantando una alarma social. La forma de eliminar a los prisioneros conmocionó a la opinión pública maliense cuyo gobierno vio la mano de AQMI, en colaboración con los tuaregs rebeldes. Una comisión de investigación puesta en marcha por el gobierno de ATT confirmó la participación de AQMI en el asesinato y las potencias extranjeras así lo corroboraron apoyando la versión de ATT.
} 


\section{El golpe de estado en Bamako y el colapso de la administración maliense}

Aunque no es el tema principal de nuestro trabajo, creemos conveniente mencionar la crisis en el sur provocada por el golpe de Estado del 22 de marzo de 2012. El 21 de marzo, durante la visita del ministro de Defensa a la guarnición militar de Kati, a 15 kilómetros de la capital, un grupo de jóvenes oficiales se sublevaron en armas. Tomaron el camino de Bamako y asaltaron el palacio presidencial y la televisión pública. Después de varias horas de confusión, de madrugada un grupo de militares con el joven capitán Amadou Haya Sanogo a su cabeza leyeron un comunicado en la televisión anunciando la consecución del golpe de Estado. Las razones de la asonada estaban relacionadas con el conflicto en el norte.

Los jóvenes militares golpistas comunicaron la creación de una junta militar llamada el Comité National pour le Redressement Démocratique et Restauration de l'Etat (CNRDRE), y justificaron la toma del poder por la mala gestión de la guerra en el norte del país por el presidente ATT. El ejército había sufrido humillantes derrotas frente a las fuerzas rebeldes y el ánimo de las tropas cada vez era más bajo ante la incapacidad política y militar del Estado. Además de tener razones para desalojar del poder político a ATT por la pésima gestión del conflicto, los soldados de la junta militar también justificaron la necesidad del "acto" para "salvar" el país que estaba contaminado por la corrupción y nepotismo en la administración y el ejército. Los golpistas no encontraron grandes oposiciones a su acción ni grandes muestras de apoyo político al presidente derrocado y gozaron de cierto apoyo popular indirecto ${ }^{25}$.

El desconcierto generado por el golpe de Estado en la cadena de mandos militares fue aprovechada por los grupos rebeldes para terminar de conquistar el norte. En apenas dos semanas el MNLA, en colaboración con una suerte de coalición de distintos grupos armados, tomaron las principales ciudades norteñas. El 5 de abril, el MNLA informó del fin de las operaciones militares y un día después, libre de la presencia de tropas del ejército maliense por primera vez en 60 años, declaró la independencia del Azawad. Sin embargo, la conquista del norte de Mali o lo que los tuaregs llaman el Azawad dio paso progresivamente a un dominio islamista. A pesar de la euforia inicial por la expulsión de las tropas de Bamako, la situación del MNLA cambió rápidamente. El movimiento secesionista obtuvo serias derrotas en los territorios conquistados a mano de los grupos islamistas y yihadistas con los que había formado una alianza militar para enfrentarse al ejército. El movimiento fue desbancado de Tombuctú por el grupo islamista Ansar Din y por Al Qaeda en el Magreb Islámico (AQMI), y tras feroces combates sus miembros fueron expulsados de Gao por el Movimiento por la Unicidad y la Yihad en África del Oeste (MUYAO).

\section{4. ¿Un estado islámico y yihadista en el Sahel?}

Como pasaremos a ver a continuación, la crisis del norte del Mali también descansó sobre elementos étnicos y de memoria histórica que los residentes del norte poseen. Los largos años de rebeliones y los excesos de los combatientes tuaregs también han generado hastío entre la población maliense en general, y en especial entre los residentes del norte de otras etnias no

\footnotetext{
${ }^{25}$ Para más información sobre el golpe de Estado protagonizado por el capitán Amadou Haya Sanogo, véase, Nievas Bullejos, David: "Mali: del golpe de Estado a las elecciones presidenciales", Cuadernos Fundación Manuel Giménez Abad, no 5 (junio 2013), en

http://www.fundacionmgimenezabad.es/images/Documentos/Cuadernos/5_cuadernos_junio2013.pdf.
} 
tuareg que también han sufrido las consecuencias de la lucha por la autodeterminación ${ }^{26}$. En el pasado se crearon movimientos populares armados en torno a etnias, como los Ganza Izo ("hijos de la tierra", de etnia songhai) y se alzaron en armas con el apoyo de Bamako. En la reciente rebelión, estas milicias estuvieron en alerta desde el inicio para contrarrestar la ofensiva tuareg. Esta animadversión entre las poblaciones no tuaregs exacerbada desde hace un tiempo por la ausencia del gobierno maliense fue sabiamente manipulada por los grupos islamistas y yihadistas que, con la ayuda de un discurso religioso que en principio no es excluyente por la etnia, lograron expulsar al separatista MNLA de las localidades conquistadas y adueñarse del norte del país ${ }^{27}$.

Además de abundar en la sensación de desorden y animadversión producida por la ocupación del MNLA, los grupos armados se apoyaron en su gran capacidad armamentística y adquisitiva. Gracias al dinero proveniente de la "industria del secuestro" y su controvertida relación con los tráficos ilícitos y de estupefacientes en el Sahel, pudieron ofrecer a la población local cierto alivio económico y social. Estos grupos se esforzaron en mejorar las condiciones de vida de la población local en contraposición con el dominio tuareg e incluso llegaron a atraer a jóvenes malienses refugiados en el sur por la breve bonanza que lograron imponer en sus dominios ${ }^{28}$.

\subsection{La yihad saheliana}

Del mismo modo que la actual crisis en el norte de Mali no se entendería sin una aproximación histórica a la cuestión tuareg, debemos tener en cuenta la presencia en el norte del país desde la última década de grupos criminales y yihadistas de ascendencia argelina. Asimismo, la reciente aparición de grupos armados con ascendencia local, apoyados en el narcotráfico, ha terminado por desangrar aún más las heridas del norte del país.

Al Qaeda en el Magreb Islámico (AQMI) y el Movimiento por la Unicidad y la Yihad en África del Oeste (MUYAO) son considerados grupos terroristas, autodenominados yihadistas en su funcionamiento y objetivos, si bien su forma de actuar y su región de influencia son diferentes. Hasta el inicio de la rebelión, estos grupos armados actuaban en la clandestinidad en el desierto y en las ciudades beneficiándose del laxismo del que ha sido acusado el gobierno de Bamako, y ligados al tráfico de estupefacientes, del que también se sospecha han participado altos oficiales del ejército y de la administración del Estado ${ }^{29}$. Tras el inicio de la rebelión tuareg, estos grupos participaron de los ataques tuaregs formando una coalición oficiosa con un objetivo común, derrotar al ejército maliense. Debido a su poderío

\footnotetext{
${ }^{26}$ Según un informe de Amnistía Internacional, no solo los abusos islamistas fueron denunciados. Un gran parte de los abusos cometidos durante la rebelión son protagonizados por miembros del MNLA. También por las fuerzas de seguridad malienses. La asociación de todos los tuaregs con el secesionista MNLA provocó la violenta reacción de parte de la población civil que se tomó la justicia por su mano contra comunidades tuaregs presentes también en el sur del país que fueron agredidas en actos de revancha, como se informó en los primeros días de la rebelión; International Amnesty: "The civilians bear the brunt of the conflict", Amnistía Internacional (septiembre 2012), en http://www.amnesty.org/pt-br/library/asset/AFR37/007/2012/en/4798153b-b5c1-4362b43a-5a0668bebf21/afr370072012en.pdf.

${ }^{27}$ Tinti, Peter: "Understanding nothern Mali: Local Context is Everything”, Think Africa Press, 28 de agosto 2012, en http://thinkafricapress.com/mali/rethinking-intervention-northern-mali-gao-timbuktu-kidal-azawad . Thiam, Adam: "Après des heures d'affrontement, les salafistes chassent le MNLA de Gao: le film des événements", Le Républicain, 28 de junio 2012, en http://www.maliweb.net/news/insecurite/2012/06/28/article,76154.html.

${ }^{28}$ La extensión de una cierta bonanza proporcionó legitimidad inicial a los grupos armados islamistas que ocuparon el territorio; "Islamists lure back northeners", Humanitarian News and Analysis, 18 de octubre 2012 , en http://www.irinnews.org/report/96578/mali-islamists-lure-back-northerners.

${ }^{29}$ Lecocq et al., op, cit., p 16; Lacher, op. cit., p 10.
} 
armamentístico y su número de combatientes fueron un actor importante en la ofensiva inicial de la que se sospecha que se benefició el MNLA. Con la retirada del gobierno de Bamako de la mitad norte del país, estos grupos pasaron a expulsar al MNLA de sus posesiones y se repartieron el control de las principales ciudades y regiones. De este modo pasaron a administrar y gestionar ciudades y poblaciones, un desafío que solventaron apoyándose en un primer momento en las viejas rencillas locales y en afiliaciones clánicas. Su condición de extranjeros, cuyos líderes son argelinos y mauritanos y la presencia en sus filas de combatientes provenientes de países de la región, en especial en AQMI, añadido a la implementación de una ley islámica ajena a la práctica tradicional religiosa de la zona, hizo sentir una desconfianza y un desapego por los residentes locales que, sin embargo, no evitó el reclutamiento en el ámbito local y el relativo y temporal alivio de la situación de los residentes ${ }^{30}$.

Aunque se sabe poco del Movimiento por la Unicidad y la Yihad en África Occidental (MUYAO), se cree que es una escisión de Al Qaeda en el Magreb Islámico relativamente reciente. En octubre de 2011 anunciaron la existencia del grupo con motivo del rapto de tres cooperantes europeos, dos de ellos españoles, en el campo de refugiados de Tindouf, Argelia. Desde entonces el grupo ha reivindicado la expansión de la yihad armada a todo el África Occidental y ha hecho hincapié en que sus miembros y líderes no son argelinos, en contraposición con AQMI. MUYAO tiene un componente local del norte de Mali importante. A la cabeza del grupo se encuentran un mauritano y un maliense de etnia árabe, una de las etnias muy presentes en el norte de Mali.

Tras el inicio de la rebelión y la posterior retirada del ejército maliense, MUYAO se instaló en la región de Gao, en el extremo este del país, y concretamente se esforzó en ocupar la ciudad de Gao, de donde se cree que provienen la mayoría de sus miembros. El grupo yihadista se financia con el secuestro de ciudadanos extranjeros a cambio de un rescate ${ }^{31}$ y con el negocio del contrabando de cocaína, donde Gao mantiene una posición estratégica ${ }^{32}$. Como apuntan algunos observadores, el grupo camina entre la frontera de grupo criminal dedicado al secuestro y al tráfico de estupefacientes y el grupo terrorista yihadista. A pesar de su gran interés en el tráfico de cocaína que atraviesa en norte de Mali, no se puede desdeñar su vertiente terrorista yihadista demostrada con la colocación de un coche bomba en una comisaría en Tamanrasset en 2012 y los coches bomba en Arlit (Níger), Kidal y Menaka, reivindicados por el grupo en 2013. Pero durante la ocupación entre abril de 2012 y enero de 2013 se esmeró en la aplicación de la sharía en sus dominios ${ }^{33}$. Fue contradictorio ya que pudo afianzarse en la ciudad de Gao. Después de expulsar al MNLA, los miembros de MUYAO distribuyeron víveres y ayuda entre la población, mayoritariamente songhai, ganándose su apoyo pero al mismo tiempo aplicaron las severas penas corporales de la implementación rigorista de la sharía y medidas impopulares como la destrucción de mausoleos o la prohibición de escuchar música, granjeándose la protesta de los residentes. Miembros de MUYAO protagonizaron casos de amputaciones de manos y pies pero las

\footnotetext{
${ }^{30}$ La sospecha de que militantes nigerianos de Boko Haram viajaron al norte de Mali para sumarse a AQMI y la presencia de otros combatientes extranjeros siempre ha sido una constante desde que los grupos islamistas tomaron el control en el norte de Mali; Issoufou, Mahamadou: "Des djihadistes afghans et pakistanais sont presents au Mali", Jeune Afrique, 8 de junio 2012, en http://www.jeuneafrique.com/Article/ARTJAWEB20120608093359/\#.T9Ne0u83Gys.twitter.

${ }^{31}$ Después de la conquista de Gao, MUYAO secuestró a 7 funcionarios argelinos del consulado de Argelia en Gao en abril de 2012. Desde noviembre de 2012 el grupo mantiene en cautiverio a un ciudadano francoportugués secuestrado en Diéma.

${ }^{32}$ Lebovich, Andrew: "Mali's bad trip", Foreign Policy, 15 de marzo 2013, en

http://www.foreignpolicy.com/articles/2013/03/15/mali_s_bad trip.
${ }^{33}$ Ibid.
} 
protestas y reacciones de la población residente también llegaron a provocar el retraso de algún castigo ${ }^{34}$. Con las sumas de dinero obtenido, la cooptación y la manipulación del hastío de la población hacia los secesionistas tuaregs, inicialmente MUYAO logró instalarse cómodamente en sus dominios en Gao. Sin embargo, su severidad en la aplicación de su versión de la justicia islámica y la aparente arabización del grupo sembró dudas entre los residentes ${ }^{35}$.

En cuanto a AQMI, el germen de la organización se implantó en el norte de Mali alrededor del 2003. Tras la derrota del Grupo Islámico Armado (GIA) en Argelia, el Grupo Salafista de Predicación y Combate (GSPC) se refugió en las comunidades del desierto del norte de Mali aprovechando la debilidad de las estructuras de autoridad de los Estados del Sahel. Se cree que los líderes argelinos estrecharon lazos de sangre con las poblaciones locales, como uno de sus líderes, el argelino Mojtar Belmojar que tomó en matrimonio a una mujer local, asegurándose la simpatía y la colaboración de los autóctonos. Asimismo, también se ganaron la integración en estas comunidades mediante la aportación de servicios que el débil Estado deniega a estas comunidades lejos del control gubernamental ${ }^{36}$. En 2007, el líder de la organización, el argelino Abdelmalek Droukdel, anunció que la red pasaba a denominarse Al Qaeda en el Magreb Islámico sometiéndose a las órdenes de Al Qaeda central como franquicia en el norte de África. AQMI se ha establecido cómodamente en el norte de Mali, beneficiándose también de una controvertida política del presidente ATT que le permitió tener una gran logística y organización en el desierto en los últimos años ${ }^{37}$. Tras el éxito inicial de la rebelión tuareg en 2012 la organización no dudó en sumarse a ella con el objetivo de crear un Estado Islámico y yihadista en el norte de Mali. Su gran potencial armamentístico distribuido en las diferentes qatibas o brigadas repartidas geográficamente en el desierto del Sáhara reportó un importante peso en la conquista. La organización pasó a controlar durante varios meses de 2012 la ciudad y región de Tombuctú, que se cree que compartió con Ansar Din.

La diversidad de actores y las alianzas locales que estos grupos mantuvieron con facciones locales para controlar el territorio hizo necesario huir de la simplificación del conflicto como un problema tuareg o como un problema de terrorismo internacional. La frontera entre los grupos en liza es muy débil en un contexto tan poroso como es el Sáhara. La colaboración entre los grupos armados durante el inicio de la rebelión a principios de 2012 fue frecuente, evaporándose sobre el terreno de batalla la condición de terroristas de unos y otros por la lucha por un mismo objetivo. La colaboración puntual, o simplemente evitarse unos a otros, fue habitual en un espacio donde, a pesar de ser un espacio amplio, los ejes de carreteras y los puntos estratégicos de aprovisionamiento son escasos, y por lo tanto, tuvieron que ser cooperativos. El apoyo a estas organizaciones por las facciones locales estuvo muy

\footnotetext{
${ }^{34}$ Para más información: Lebovich, Andrew: "Trying to understand MUJWA", Al Wasat (Blog). The Muslim world, radicalization, terrorism, and ideology, (22 de agosto 2012), en http://thewasat.wordpress.com/2012/08/22/trying-to-understand-mujwa/.

35 Tinti, Peter (2013): “The Jihadi from the block”, Foreign Policy, 19 de marzo 2013, en http://www.foreignpolicy.com/articles/2013/03/19/jihad_mali_al_qaeda_gao.

${ }^{36}$ Sobre la instalación del terrorismo yihadista en el desierto de Sáhara, también conviene señalar la polémica teoría del antropólogo Jeremy Keenan. El investigador Keenan sostiene que el GSPC, y el posterior AQMI, es una creación de los servicios secretos argelinos con el beneplácito de los Estados Unidos y que sus principales líderes son agentes de la DRS. Para más información sobre esta teoría , Keenan, Jeremy (2009): The Dark Sahara: America's War on Terror in Africa, London, Pluto Press.

${ }^{37}$ Para más información sobre el laxismo del gobierno de ATT para con AQMI y la posible connivencia a causa del tráfico de la droga, véase, Lacher, Wolfram: "Organised crime and conflict in the sahel-sahara region", Carnegie Endowment for International Peace (septiembre 2012), en http://carnegieendowment.org/files/sahel_sahara.pdf.
} 
dividido por las afiliaciones clánicas y étnicas y por la prestación de servicios y de dinero que ofrecieron a los individuos que no comulgaron necesariamente con la ideología y sus objetivos. Prueba de ello fue el grupo Ansar Din. Durante el proceso de negociación emprendido por la mediación africana este grupo no llegó a rechazar frontalmente a AQMI y MUYAO como se le exigió lo que le valió siempre la sospecha de ser yihadista. Sin embargo, es poco probable que hubiese dado ese paso puesto se benefició de su alianza temporal con estos grupos por su potencial y su gran poder adquisitivo. Estos beneficios los utilizó para seguir ejerciendo su influencia, si bien sus objetivos eran diferentes a los de estos grupos como veremos a continuación.

\subsection{La emergencia del islamismo en clave local}

Otro de los actores en este conflicto es el grupo tuareg e islamista Ansar Din (a menudo traducido como "Defensores de la fe"). Es un movimiento compuesto fundamentalmente por tuaregs de los Ifoghas y está liderado por el tuareg maliense Iyad Ag Ghali. Como uno de los principales líderes que iniciaron el levantamiento de los años noventa, Ag Ghali es un viejo conocido de la política maliense y regional. Tras el inicio de la reciente rebelión, Ansar Din fue de los grupos más activos militarmente que le hicieron ser uno de los actores centrales de la crisis en el norte de Mali. La conversión de su líder a un islamismo político ha dado lugar a numerosas conjeturas sobre la verdadera razón de ser de Ansar Din, si es un elemento más de la internacional yihadista o si es una emergencia política local más del problema del norte de Mali.

La trayectoria de Iyad Ag Ghali ha sido controvertida en el seno del movimiento tuareg. Hijo de un tuareg fallecido en la primera rebelión de 1962, se crió dentro del clan de los Ifoghas, clan considerado como la nobleza o elite en la compleja estructura tribal ${ }^{38}$. Como muchos jóvenes de la comunidad tuareg, el joven Ag Ghali se vio forzado a la emigración en los años setenta y ochenta. Durante esos años estuvo al servicio del líder libio Gadafi, combatiendo en el extranjero donde aprendió habilidades militares. En los años noventa, fue llamado por el movimiento maliense para la rebelión que se estaba iniciando frente al tambaleante régimen militar de Moussa Traoré. Ag Ghali fue uno de los principales líderes de la rebelión. También fue el líder tuareg que aceptó la negociación con Bamako para calmar la insurrección, algo que una parte del movimiento nunca aceptó ni le perdonó. Su cercanía con Bamako tras los polémicos acuerdos le valieron las acusaciones de traición y de colaborar con el Estado de un parte de la comunidad tuareg.

Al líder tuareg se le ha descrito en muchas ocasiones como un pragmático oportunista ${ }^{39}$. Por oportunismo o no, ha sido el personaje que ha traído el islamismo político al norte de Mali mezclándolo con unas preocupaciones locales. Ha abrazado la causa islamista y ha intentado implantarla en el movimiento tuareg. Desde el final de la fracasada rebelión de los noventa, Iyad Ag Ghali empezó a interesarse en el islam que predican los miembros del Tabligh a Jama'a o Da'wa, como también es conocida, desde los años noventa en Mali. El Tabligh es una organización misionera de origen indio que predica un islam piadoso en todo el mundo y que busca reconducir al musulmán a la práctica correcta. Esta organización

\footnotetext{
${ }^{38}$ El clan también posee una legitimidad religiosa atribuida por el trazado de sus antepasados hasta el Profeta. Mcknight, Joe: "Iyad: An epic of modern Mali", The Revealer, 16 de octubre 2012, en http://therevealer.org/archives/13713.

${ }^{39}$ Lloyd George, William: "The Man Who Brought the Black Flag to Timbuktu”, Foreign Policy, 22 de octubre 2012, en

http://www.foreignpolicy.com/articles/2012/10/22/the man_who_brought the black_flag to timbuktu?page=0, $\underline{0 .}$
} 
misionera rechaza posicionarse políticamente además de refutar la violencia y la yihad, y aunque aboga por el seguimiento de la sharía no significa una inmediata radicalización y un pase a la yihad, de hecho no hay evidencias de radicalizaciones masivas por la Da'wa en África del Oeste. A pesar de que la mayoría de los tuaregs reniegan de ese islam, el seguimiento de la práctica piadosa de la Da'wa ha aumentado en África del Oeste en general, y en el norte de Mali en particular, en reacción a la extensión de la corrupción del Estado y de las debilidades de éste en materia económica y social. Además de por estos motivos, tuvo bastante aceptación en el clan de los Ifoghas por rivalidades políticas ${ }^{40}$. La conversión de Ag Ghali en un personaje piadoso sorprendió a la mayoría de sus compatriotas puesto que, aunque de religión musulmana, al parecer no era muy celoso de la práctica religiosa. Iyad era conocido por su afición a la bebida y los cigarrillos ${ }^{41}$. Algunos observadores creen que el líder tuareg acudió a Paris y Pakistán donde frecuentó mezquitas del Tabligh ${ }^{42}$.

A su regreso al norte de Mali, Ag Ghali ejerció como intermediario entre el gobierno maliense, los gobiernos occidentales y los grupos terroristas para la liberación de los 32 rehenes europeos capturados en 2003 en el Sáhara. En esta época se cree que cosechó relaciones con históricos miembros de AQMI, llegando incluso a tejer unos lazos sanguíneos con algún líder, lo que a menudo se utiliza para ubicarlo dentro del movimiento yihadista magrebí $^{43}$. Años más tarde, durante el inicio de la rebelión en 2006 en la que también participó, dejó claro que su islamización no significaba un apoyo a las prácticas yihadistas de los grupos terroristas de la zona ya presentes en ese momento ${ }^{44}$. En un telegrama filtrado por Wikileaks de la embajada de Estados Unidos en mayo de 2007, Iyad comentaba la implantación de AQMI en la región, pero estimaba que la organización de Ben Laden tenía poco arraigo por la ideología extremista que importaba a la población tuareg del norte. De hecho, reclamaba un apoyo del gobierno maliense y estadounidense para expulsar a la franquicia de Ben Laden de allí, algo que hoy puede contrastar con las sospechas sobre él y su grupo por mantener una estrecha colaboración con la organización terrorista en los acontecimientos de 2012 y 2013 ${ }^{45}$. En 2008, en cumplimiento de los acuerdos de 1992 que prevén el envío de representantes tuaregs en el exterior, Iyad fue enviado como asesor al Consulado de Mali en Jeda. Imbuido de un islam piadoso, es en Arabia Saudí donde algunos observadores sospechan que adoptó una radicalización política que le ha llevado a militar ${ }^{46}$. Sus aparentes flirteos con grupos religiosos extremistas le hicieron ganarse la expulsión por parte de las autoridades saudíes en pocos meses ${ }^{47}$.

De vuelta en Mali, en 2011 con el inicio de la gestación de la nueva rebelión tuareg, Iyad intentó erigirse en líder del movimiento insuflándole un matiz religioso. Esto no fue aceptado por una parte del movimiento y, añadido a sus oscuras relaciones con Libia y Argelia y sobre todo con Bamako, le auguró el rechazo durante la conformación del MNLA.

\footnotetext{
${ }^{40}$ Lecocq y Shrijver, op. cit., p 149.

${ }^{41}$ Mcknight, op. cit.

42 Ibid., p 150. En su argumentación sobre el impacto del Tabligh entre los Ifoghas, Mcknicht menciona un chiste extendido en el norte de Mali sobre Iyad Ag Ghali y su conversión a observar un islam más piadoso. En el mundo tuareg se dice que si en los años 90 llegabas a la puerta de Iyad por la mañana y el guarda te decía que estaba indispuesto es que había estado todo la noche bebiendo, y que si llegas ahora a su puerta y el guarda te dice que está indispuesto es que ha estado rezando toda la noche.

${ }^{43}$ Se cree que al Targui, el líder tuareg que lidera una pequeña qatiba de AQMI, es sobrino de Iyad.

${ }^{44}$ Lecocq y Shrijver, op. cit., p 155.

${ }^{45}$ Lloyd George, op. cit.

${ }^{46}$ Ostebo, Terje: "Le militantisme islamique en afrique", Bulletin De La Securité Africaine, Centre d'Etudes Strategiques De l'Afrique, $\mathrm{n}^{\circ} 23$ (septiembre 2012), en http://reliefweb.int/sites/reliefweb.int/files/resources/AfricaBrief_23_French.pdf.

${ }^{47}$ Morgan, op. cit.
} 
Su ferviente visión religiosa del movimiento tuareg le valió una falta de apoyos para liderar, en primer lugar, el movimiento rebelde y, más tarde, para denominarse el sucesor del Amenokal o jefe supremo tradicional tuareg. Apartado de la escala de poder a pesar de haber sido una gran figura en los años noventa, se decantó por la fundación de su propio movimiento, Ansar Din, con el fin de instaurar la sharía en la zona sin olvidar las históricas reivindicaciones tuaregs.

Su influencia espiritual y prestigio militar dentro de una parte de la comunidad tuareg seguía vigente y lejos de no predicar atrajo a numerosos seguidores y personajes de renombre, incluso de dentro de las filas del MNLA. Tomando el islam como bandera también intentó sobrepasar las divisiones entre clanes tuaregs y entre etnias en el norte de Mali y con ello hacer posible la idea de controlar una amplia zona no necesariamente circunscrita a donde existieran apoyos al proyecto secesionista tuareg. Si bien su movimiento siempre ha estado liderado por tuaregs de los Ifoghas y sus principales preocupaciones y reivindicaciones eran ampliamente tuareg, como demuestra la plataforma política que anunciaron a principios del año 2013 en la que un gran porcentaje de las reivindicaciones tenían como objeto la cuestión tuareg $^{48}$. Además de abogar por la implantación de la sharía, se ha reclamado en contra de la secesión del Azawad de Mali, enfrentándose a la principal reivindicación del MNLA. La creación de Ansar Din y su relación con AQMI parece enmarcarse en unas rivalidades personales y de influencias en la fragmentada sociedad tribal tuareg, y del pragmatismo del que Iyad hace gala, apostando por unas alianzas que le reportaron una clara ventaja militar. De esta manera podemos considerar que reclutó y atacó en lo profundo de la corriente del MNLA, en especial en la zona de Kidal de donde Iyad y el clan de los Ifoghas son originarios.

Durante la rebelión, Ansar Din participó en la toma de las principales ciudades del norte en colaboración con el resto de movimientos armados, en especial con AQMI. Las alianzas con brigadas militares de esta organización fueron sobre todo en base a afinidades clánicas y alianzas temporales como la que les permitió controlar la ciudad de Tombuctú gracias a los árabes berabiches aliados de AQMI y las tribus tuareg aliadas en la zona de Kidal. ¿Por ello se puede considerar a Ansar Din un grupo yihadista? Como hemos visto, la emergencia de este grupo se debe en especial a las tensiones locales y las preocupaciones locales de su líder que tomó el islamismo político para insuflar un nuevo impulso a su proyecto. Otros aspectos también diferenciaron a este grupo del resto de grupos autodenominados yihadistas. Al contrario que AQMI y MUYAO, desde el inicio de las hostilidades Ansar Din se mostró abierto al dialogo con la mediación africana en el conflicto y con el Estado maliense. Especialmente, el grupo accedió a la liberación de varios cientos de soldados capturados en la batalla, así como la apertura de un corredor humanitario para las poblaciones de Gao y Tombuctú. Por otro lado, Ansar Din estaba compuesto por históricos líderes tuaregs como Alghabass Ag Intallah, hijo del Amenokal o jefe tradicional de los Ifoghas, o Mohamed Ag Bibi diputado tuareg en la Asamblea Nacional de Mali. No obstante, el movimiento de Iyad se mostró intransigente en una de sus principales reivindicaciones, la aplicación de la ley islámica en Mali. Este extremo también fue objeto de modificaciones pragmáticas del grupo. En un principio, el deseo de Ansar Din era la aplicación de la sharía en todo el territorio de Mali, algo que podía conectar con la ideología más internacionalista de los grupos yihadistas. Conforme avanzaron las negociaciones, la reivindicación del grupo era la aplicación de la sharía únicamente en sus dominios y en la zona de origen de los Ifoghas, en Kidal, con un claro componente local. Esta estrategia no les impidió ser de los más activos en la destrucción

\footnotetext{
48 Ansar Din: “Communiqué: Plateforme Politique d'Ansar Din”, ansaradinne.be, 6 enero de 2013 en http://afrinoticias.wordpress.com/2013/01/06/communique-la-plateforme-politique-dansar-dine/.
} 
de los lugares de peregrinación y devoción de las poblaciones musulmanas residentes en la zona y en la ejecución de castigos corporales emanados de la aplicación de la sharía según sus líderes. Como en el caso de la imposición de castigos corporales por los otros grupos armados, estas prácticas provocaron la protesta de los residentes y el distanciamiento social. La población lo vio como alejado de su tradicional forma de vivir el islam.

\subsection{El fracaso de la negociación y la ofensiva islamista-yihadista sobre el centro de Mali}

La crisis del norte de Mali motivó la preocupación de las potencias occidentales. Además de la creciente inestabilidad, la expulsión del MNLA y la ocupación del norte de Mali por grupos islamistas y yihadistas también aumentó la preocupación de los países del entorno. Los Estados vecinos propugnaron una intervención y presionaron a la presidencia interina maliense para que en septiembre de 2012 pidiese formalmente la intervención militar de la ONU. Con la determinación de Francia por la intervención y el visto bueno de EEUU, el Consejo de Seguridad de la ONU aprobó las resoluciones 2071 y 2085 que acataron la petición de intervención militar a cargo de la CEDEAO con un apoyo internacional.

El 1 de enero 2013 Ansar Din declaró que se retiraba de las negociaciones y que volvía a retomar las hostilidades, alejándose así del acuerdo alcanzado un mes antes con la mediación africana, encabezada por el presidente burkinés Blaise Compaoré, en la que se comprometía a cesar las hostilidades y rechazaba el terrorismo. Pocos días después, un gran contingente de milicianos armados encabezados aparentemente por el propio Iyad Ag Ghali, cruzó la línea tácita de separación que dividía el frente en el centro-sur del país. La pequeña ciudad de Konna, situada a 70 kilómetros de la primer gran centro urbano del centro-sur de Mali, Mopti, con cerca de 115.000 habitantes, cayó en manos de los combatientes islamistas. Pero el enclave importante era la cercana localidad de Sévaré, donde existe una base militar y un aeropuerto que era clave para cualquier plan de reconquista del norte por cualquier ejército así como el despliegue de fuerzas internacionales que se estaba concretando, aunque lentamente, con el auspicio de la ONU. La vulnerabilidad a la que estaba expuesta esta estratégica base militar, además de la posible, aunque bastante remota, amenaza sobre Bamako, a más de 800 kilómetros al sur, hicieron que el 10 de enero el presidente interino Dioncounda Traoré pidiera ayuda militar a Francia y la ONU para frenar el avance islamista y yihadista. Esto propició la ofensiva militar aérea y terrestre de Francia y el posterior despliegue militar africano. París se inspiró en la resolución 2085 de la ONU para actuar y su intervención ayudó a acelerar el despliegue militar de la Misión Internacional en Apoyo a Mali bajo Liderazgo Africano (MISMA en sus siglas en francés) que anteriormente no había sido previsto para antes septiembre de 2013.

El hecho de que Ansar Din se retirase del proceso de negociación africana sigue sin explicación. No tenemos pistas para conocer las razones de tal acción, pero los interrogantes persisten teniendo en cuenta que en apenas un mes el grupo pasó de ser muy activo en la negociación y rechazar las hostilidades y el terrorismo en diciembre de 2012, a participar y presumiblemente a impulsar un ataque de gran envergadura. Según sus portavoces, uno de los motivos de la ofensiva fue que Bamako, que no estaba todavía en las conversaciones, no hacía nada por mejorar la situación, manteniendo una postura aparente de desprecio hacia la negociación. Bamako pretendía incorporarse más tarde aunque existía la sensación de que retrasaba el diálogo con los grupos armados. 


\subsection{Hacia la normalización política y securitaria: la intervención militar internacional y la celebración de elecciones presidenciales}

El rápido despliegue de la operación militar francesa Serval en Mali consiguió detener la ofensiva islamista armada en el centro del país. El éxito en esta tarea continuó con la extensión de las operaciones armadas francesas en la retaguardia de los grupos armados. La imposibilidad de combatir al ejército francés, que utilizó su poderío aéreo de combate, empujó a los combatientes a cambiar de estrategia. El ataque desde el aire a bastiones armados y almacenes de armas motivó su huida. Las principales ciudades del norte de Mali, Tombuctú, Gao y Kidal, fueron reconquistadas y reocupadas progresivamente por las fuerzas francesas terrestres junto a las fuerzas de los países africanos aliados y el ejército maliense. La mayoría de los milicianos islamistas y yihadistas se refugiaron aparentemente en las montañas del Tigharghar, en la región de Kidal. Allí, en un terreno árido y montañoso, el combate ha sido más duro para los efectivos franceses y chadianos que han combatido a pie a los elementos armados. A falta de otras fuentes para contrastar las cifras, las autoridades malienses han hecho público el número de bajas de la Operación Serval. Alrededor de 63 soldados malienses, 23 soldados chadianos y cerca de 600 combatientes yihadistas e islamistas armados han fallecido en los combates ${ }^{49}$. Por su parte París ha informado de siete bajas para los hasta 4 500 efectivos que han estado comprometidos con la Operación Serval ${ }^{50}$.

Mientras las operaciones militares de reconquista se sucedían, la Asamblea Nacional de Mali votó la hoja de ruta para normalizar la situación política en el país, alterada desde el golpe de Estado de marzo de 2012. La celebración de elecciones presidenciales era uno de los principales puntos, y con el respaldo de los partidos políticos, el gobierno interino de Diouncounda Traoré comenzó con los preparativos para su organización con la ayuda internacional. Con el visto bueno, pero también con la presión de Francia y EEUU, las fechas fueron elegidas finalmente para el 28 de julio y 11 de agosto de 2013. La celebración de elecciones presidenciales era también una demanda de los socios internacionales de Mali a cambio de la ayuda de 3,2 mil millones de euros prometidos en la conferencia de donantes del 15 de mayo 2013 celebrada en Bruselas.

Mali posee un sistema electoral de doble ronda. Si uno de los candidatos no obtiene más de $50 \%$ de los sufragios expresados una segunda ronda electoral tiene lugar entre los dos primeros candidatos. Las fechas elegidas fueron criticadas por muchos observadores por ser prematuras $^{51}$. Además de que la guerra en el norte todavía estaba vigente y la inseguridad existía, la movilización de los cerca de 500.000 desplazados y refugiados malienses por la inestabilidad en el norte que no habían vuelto a sus casas no estaba asegurada. Las fechas también coincidían con el mes sagrado musulmán, el Ramadán, y con la época de lluvias que podían haber puesto en peligro la votación en alguna región del país. A pesar de la controversia de las fechas, la mayoría de los actores políticos y sociales malienses estaban de acuerdo en la celebración de las elecciones. Era necesario dar un sustituto legítimo al presidente interino y su gobierno que ya no tenían legitimidad suficiente para gestionar y

\footnotetext{
${ }^{49}$ Bamada.net: "Dernier bilan des opérations Serval et Misma: 600 islamistes, 63 soldats maliens, 26 tchadiens et 5 français tués aux combats", Afrique Magazine, 27 de junio de 2013, en http://bamada.net/exclusif-bamadadernier-bilan-des-operations-serval-et-misma-600-islamistes-63-soldats-maliens-26-tchadiens-et-5-francais-tuesaux-combats.

${ }^{50}$ Bamada.net: "Le bilan de l'opération Serval en chiffres", La voix du Nord, 23 de septiembre de 2013, en http://bamada.net/le-bilan-de-loperation-serval-en-chiffres

${ }^{51}$ International Crisis Group: "Managing Mali's elections: a short delay would pay long-term dividends", 26 de junio de 2013, en http://www.crisisgroup.org/en/publication-type/media-releases/2013/africa/managing-maliselections.aspx.
} 
tomar las decisiones que el país debe de seguir para salir de la crisis. La seguridad era asegurada en casi todo el territorio por las tropas africanas de la misión de la CEDEAO que pasaron a formar parte de la operación de estabilización de la ONU con cerca de 7000 efectivos militares y policías desplegados durante el proceso electoral. 28 candidatos cumplieron finalmente los requisitos de la Corte Constitucional de Mali y compitieron por la presidencia. Solo un candidato criticó las condiciones de la preparación de las elecciones y se retiró. Sus críticas vertieron principalmente sobre la situación de $\mathrm{Kidal}^{52}$.

La liberación del norte por las tropas francesas y africanas no ha significado una devolución de todo el territorio a la soberanía maliense. Tras su liberación, la ciudad de Kidal pasó a manos del MNLA y otras facciones tuaregs. La presencia en la ciudad de la administración y las fuerzas de seguridad malienses fue vetada hasta la firma del acuerdo alcanzado el 18 de junio 2013 en Uagadugú, Burkina Faso. El MNLA y un nuevo movimiento tuareg creado tras la expulsión de Ansar Din, el Alto Consejo por la Unión del Azawad $\left(\right.$ HCUA $\left.^{53}\right)$, se comprometieron a mantener un alto el fuego y a permitir el retorno de la administración central para la preparación de las elecciones en Kidal y su región (art.4), a cambio del compromiso del gobierno interino de que el gobierno salido de las urnas se reuniría en el plazo de 60 días con las facciones tuaregs y las comunidades del norte para negociar el futuro de la región (art.20) ${ }^{54}$. Con este acuerdo preliminar, y no sin sobresaltos y tensión en la región de Kidal, el 28 de julio y el 11 de agosto se votó al presidente en todo el territorio de Mali, aunque la participación en Kidal fue notablemente escasa en comparación con la media del país ${ }^{55}$.

Los malienses votaron para salir de la crisis política y securitaria que sufren desde enero de 2012, pero también acudieron a las urnas para decidir el futuro de su país en los próximos cinco o diez años. Mali sufre otros problemas más acuciantes además del terrorismo y la rebelión armada tuareg. Las principales demandas de la población maliense son el desarrollo socio-económico y la seguridad alimentaria, que también serán las prioridades durante los próximos de cinco años del presidente elegido, el ex primer ministro Ibrahim Boubacar Keita. El candidato del partido Rassemblement pour le Mali (RPM) ganó holgadamente las elecciones presidenciales en la segunda ronda que le enfrentó al candidato Soumaïla Cissé $(\text { URD })^{56}$. Keita, investido presidente de la República de Mali el 4 de septiembre 2013, hereda un país frágil salido de un episodio traumático, la perdida del control del norte del país y una guerra de reconquista. Sin duda los desafíos a los que se enfrenta no podrá acometerlos sin

52 "Tiébilé Dramé se retire de la course à la présidentielle", RFI, 17 de julio de 2013, en http://www.rfi.fr/afrique/20130717-mali-france-tiebile-drame-fabius-annonce-son-retrait-election-presidentiellekidal-bamako.

${ }^{53}$ El Alto Consejo por la Unidad del Azawad (HCUA) es presidido por Intallah Ag Attaher, Amenokal tuareg, miembro del clan de los Ifoghas. El HCUA agrupa a personalidades del ex Movimiento Islámico del Azawad (MIA) conformado por ex miembros de Ansar Din, liderado por Alghabass Ag Intallah, y miembros del Alto Consejo del Azawad (HCA) encabezado por Mohamed Ag Intallah. Ambos personajes son hijos del Amenokal Ag Attaher.

54 "Texte integre de l'Accord préliminaire de Ougadougou" (18 de junio de 2013), en http://www.arawanexpress.com/evitons-les-rumeurs-le-texte-exact-sign-ouagadougou-cliquez-sur-une-imagepour-voir-le-contenu/.

${ }^{55}$ La administración maliense regresó a Kidal apenas pocos días antes de la fecha elegida para las elecciones. En los días anteriores se registró una campaña en contra de las elecciones por una parte del MNLA, como el secuestro de agentes electorales en Tessalit. "Le gouverneur de Kidal de retour avec du matériel", RFI, 15 de julio de 2013, en http://www.rfi.fr/afrique/20130715-mali-le-gouverneur-kidal-retour-ville-nord-materielkamissoko

${ }^{56}$ El candidato Keita ha ganado las elecciones presidenciales con un 77,62\% de los votos. Maliweb: "Résultats définitifs de l'élection présidentielle : La victoire et le score historiques de IBK confirmés", L'Essor, 20 de agosto de 2013, en http://www.maliweb.net/news/nation/2013/08/21/article,165183.html 
una refundación del país y de sus instituciones, con la ayuda de un gobierno sólido que deberá ejercer el control civil y militar en todo el territorio mientras mantiene la paz y la estabilidad en el norte. En la tarea de devolver la estabilidad al país será asistido por la comunidad internacional con la garantía de que la posibilidad de un nuevo conflicto en el norte parece estar desactivada mientras dure el despliegue de tropas internacionales.

La respuesta militar internacional ha eliminado la mayor parte de la amenaza de grupos yihadistas e islamistas armados que ocuparon el norte de Malí. Los cabecillas de los grupos yihadistas han sido abatidos en los combates o parecen haber cruzado la frontera maliense hacia otras zonas de refugio a lo largo del Sahel ${ }^{57}$. Sin embargo, la amenaza en el norte de Mali no se ha evaporado. Estos grupos pudieron reclutar entre la población local al beneficiarse de las tensiones intercomunitarias existentes en esta compleja zona y de la mala gestión durante años del presidente ATT. Incluso, comunidades en la región de Gao donde al parecer desde hace años se practica una forma de vivir el islam más rigorista y más cercana al wahabismo, han sido más sensibles al mensaje de estos grupos islamistas y yihadistas. Estas comunidades han llegado a cobijar a combatientes después de la liberación del norte, lo que explicaría la persistente capacidad operativa del movimiento MUYAO ${ }^{58}$. Durante los últimos meses este grupo ha protagonizado varias acciones armadas contra las tropas malienses e internacionales en el norte del país, incluso operaciones suicidas en Gao y otras localidades norteñas ${ }^{59}$. La erradicación final del terrorismo y del extremismo, y el regreso de la convivencia y la paz entre comunidades dependerá de lo que el gobierno del presidente Keita haga en el norte, de si promoverá el desarrollo y la inversión y de si atenderá las necesidades de las poblaciones acompañado de un regreso del Estado y de la seguridad.

\section{Conclusiones}

Para concluir este trabajo, nos gustaría destacar algunos factores que nos ayudan a entender la crisis maliense. En nuestra opinión, no podemos reducir el conflicto del norte de Mali a un problema de terrorismo internacional. Asimismo, el problema tuareg no se puede aislar para explicar la caída en el abismo. Como hemos comentado en las líneas más arriba, la crisis actual que vive Mali está imbricada en un complejo conflicto de carácter interno. Por tanto, el repaso al estallido de la rebelión tuareg del 2012 y la posterior ocupación por parte de grupos yihadistas e islamistas entre abril 2012 y enero de 2013 nos permite entender el foco de inestabilidad y de tensión que existe en el norte de Mali.

A pesar del papel desestabilizador que desempeñaron los grupos islamistas y los yihadistas extranjeros, en su mayoría argelinos, haciendo de la rebelión tuareg una insurrección diferente, estos se asentaron sobre tensiones y reivindicaciones preexistentes locales que no se han resuelto en los últimos años. Como es habitual en otros lugares del mundo, las redes yihadistas han parasitado cualquier atisbo de inestabilidad, en este caso el problema tuareg, y se han visto agraciados por las deficiencias en la prestación de servicios del Estado maliense y por el incremento de tráficos ilícitos hacia Europa, como los

\footnotetext{
57 “AQMI confirme la mort d'Abou Zeïd”, Le Monde, 16 de junio de 2013, en http://www.lemonde.fr/afrique/article/2013/06/16/aqmi-confirme-la-mort-d-abou-zeid_3430983 3212.html. ${ }^{58}$ Maliactu: "Ile de Kadji : arrestation de 50 presumes complices du MUJAO”, L'Essor, 4 de marzo de 2013, en http://maliactu.net/ile-de-kadji-arrestation-de-50-presumes-complices-du-mujao/

59 "Guérilla urbaine à Gao", RFI, 11 de febrero de 2013, en http://www.rfi.fr/afrique/20130211-mali-guerillaurbaine-gao-mujao-france-afrique-ouest.
} 
estupefacientes que atraviesan el Sahel. A las históricas reivindicaciones de una parte de la comunidad tuareg insatisfecha con la aplicación de los anteriores procesos de paz y el desarrollo económico del norte, se añadió la deficiente gobernanza del norte del país por las autoridades de Bamako. En especial los últimos años del gobierno del presidente ATT (20022012) fueron desastrosos, dejando el control del norte en manos de tribus tuaregs y árabes que tuvieron manga ancha para participar del creciente y lucrativo tráfico de la droga y exacerbando las tensiones interétnicas. La inexistente defensa y apoyo popular demostrado hacia ATT durante el golpe de Estado que lo apartó del poder prueba el descontento generalizado por su segundo mandato y la poca confianza en la democracia que ofrecían las elecciones previstas para un mes después. Tampoco podemos olvidar el hartazgo de una parte del ejército que se levantó en contra de la gestión del conflicto y de la pésima situación del ejército.

Los abusos cometidos por los grupos yihadistas e islamistas que durante 10 meses dominaron el norte de Mali y la presencia más o menos abultada de los personajes terroristas internacionales no deberían de desviar la atención de los factores sobre los que descansó la ocupación. La vida bajo la sharía llevó el sufrimiento y la desesperación a la población residente en el norte. Las lapidaciones, flagelaciones y amputaciones de manos y pies bajo el amparo del islam fueron rechazadas y contestadas por gran parte de la población musulmana local, pero debido a factores locales que hemos intentado desgranar en este artículo el dominio islamista fue en gran parte pacífico. Es sabido que el islam en Mali, mayoritariamente sufí, es tenido como un islam quietista y moderado que se aleja de todo extremismo, aunque esto no es exacto del todo si nos acordamos de las yihad sufíes de los siglos XIX en África del Oeste. Este islam místico contrasta con el islam más extremista que los grupos armados impusieron, pero sin duda éstos fueron capaces de conectar con sectores sociales más conservadores y con clases más desfavorecidas. Esto no explica que toda la población, independientemente de su origen étnico, aprobó la visión islamista y extremista de este islam pero nos da pistas sobre el éxito de la expulsión del MNLA y la relativa estabilidad que se vivió durante los cerca de 10 meses de dominio islamista.

Los yihadistas e islamistas hicieron creer que estaban comprometidos con el establecimiento de un Estado islámico basado principalmente en el islam y en la aplicación de una justicia y orden basado en la ley islámica que no discriminaba a los individuos por su origen étnico. Esto era visto en contraposición con el MNLA, movimiento considerado por las poblaciones locales como un epígono más del histórico movimiento que intentó imponer un dominio tuareg en el norte de Mali, algo inaceptable para la mayoría de la diversa población étnica. El recuerdo de las pasadas rebeliones y la violencia ejercida durante el breve dominio del MNLA, dieron apoyo o al menos otorgaron una visión benévola de las ideas de los grupos yihadistas e islamistas que restablecieron cierto orden y justicia, y se esforzaron en conquistar los corazones de los residentes. Pero, como hemos indicado más arriba, la dura aplicación de los castigos corporales, el exceso de moralidad en las calles y la creciente sospecha de la aplicación de castigos a clases étnicas o por venganzas personales hicieron que este apoyo se erosionase. Por otro lado, la extensión del control de estos grupos extremistas se debió en parte a la gran variedad de alianzas de conveniencia entre las distintas comunidades presentes en el desierto, rematadas por los lazos de sangre o por alianzas de fortuna que existen entre algunos de ellos, muchas veces bebiendo de afinidades clánicas o simplemente vendiendo sus lealtades sin comulgar necesariamente con la ideología y objetivos de estos grupos armados.

Por otro lado, creemos también importante destacar el ascenso del papel del islamismo político en el conflicto del norte de Mali, y como parece ser, en Mali en general. A través de la trayectoria política y religiosa del líder tuareg Iyad Ag Ghali hemos comprobado que el 
islamismo político ha tenido cabida en el país y que ha sido uno de los actores en este conflicto. A pesar de que este personaje mantiene un perfil bajo tras la intervención militar, seguramente marcado por liderar la ofensiva en el centro del país que desencadenó la reacción internacional, la centralidad de este personaje en el conflicto, manteniéndose en el filo del movimiento tuareg y los grupos yihadistas, es para tomar en consideración. Las reivindicaciones religiosas de Ansar Din con sus intereses nacionalistas y locales tuaregs hacen que se le relacione inevitablemente con el debate que se está produciendo en Mali sobre la práctica islámica y la redefinición de la relación Estado-religión, que hasta ahora ha estado basada en la laicidad heredada de la antigua metrópoli ${ }^{60}$.

A pesar del éxito de la intervención militar franco-africana iniciada enero 2013 para desalojar a las fuerzas yihadistas e islamistas que dominaron el norte de Mali, muchas de las condiciones que permitieron el estallido de la rebelión del MNLA y el surgimiento y establecimiento de las redes yihadistas, permanecen ahí. El descontento tuareg y su marginalización siguen vigentes como la creciente tensión entre las comunidades étnicas. Es necesario entender que las reivindicaciones de una parte de la comunidad tuareg son históricas y que es un problema que ningún presidente maliense ha sabido dar solución desde hace más de 50 años que dura la lucha por la autodeterminación tuareg. Aprovechando la coyuntura el nuevo ejecutivo de Ibrahim Boubacar Keita debería de dar una oportunidad al diálogo y a la reconciliación entre comunidades como se ha dado en el pasado pero poniendo el acento en cumplir las promesas de manera que no ocurra como el resto de rebeliones pasadas, que se repiten cuando la frustración tuareg no puede más.

\footnotetext{
${ }^{60}$ Mali es un país que es definido como laico por su Constitución de 1992. Sin embargo un 90\% de la población es considerada musulmana. En los últimos años los imames y líderes religiosos están teniendo un mayor papel en la "esfera pública" maliense y se percibe una mayor implicación en la política maliense. Durante la dominación del norte por los grupos islamistas, los principales líderes musulmanes no estuvieron de acuerdo con las prácticas de castigos corporales y la destrucción de mausoleos en nombre de la sharía, pero el debate en el país sobre la ley islámica en el país no es nuevo. En 2010, bajo la presión de miles de seguidores movilizados por los dirigentes musulmanes, el gobierno de ATT anuló la reforma del código de las personas y de la familia que había sido aprobada por el parlamento, reforma que era considerada contraria a la ley islámica.
} 